\title{
CHALLENGING SEXUAL VIOLENCE AGAINST GIRLS: A SOCIAL AWARENESS APPROACH
}

For final version see: Kitzinger, J. (1994) 'Challenging sexual violence against girls: A public awareness approach to preventing sexual abuse', Child Abuse Review Vol 3 no4: 246-248 ISSN 0952-9136.

JENNY KITZINGER. Cardiff University

\section{CHALLENGING SEXUAL VIOLENCE AGAINST GIRLS: A SOCIAL AWARENESS APPROACH}

\begin{abstract}
Most strategies to prevent child sexual abuse rely on therapeutic work with abusers or direct work with children training them to recognise and resist molestation. However, many authors, activists and professionals in this field assert the need to challenge broader social attitudes towards sexuality and violence. In 1992 an attempt at such an intervention was employed by Edinburgh District Council in their 'Zero Tolerance Campaign'. This was a public awareness campaign which aimed to increase people's understanding of the extent and nature of violence against women and girls and to emphasise that such crimes should not be tolerated. Through challenging misconceptions, encouraging public discussion and focusing on strategies to prevent such crimes, the campaign organisers hoped to transform the social climate which is conducive to the abuse of women at any age. This article explores public response to the Zero Tolerance Campaign and, in particular, focuses on reactions to the two advertisements which addressed the sexual abuse of girls.
\end{abstract}

\section{i. Introduction}

Child sexual abuse prevention has become synonymous with education programs for the potential victims. 'Prevention programs' aimed at children are used in every state in the USA, as well as many parts of Britain (Trudell \& Whatley, 1988). They have become a multimillion dollar industry and are the subject of an extensive literature (deYoung, 1988). Less attention has been paid to preventing sexual abuse in other ways such as challenging general public attitudes or attempting to change the social structures which facilitate abuse (see Kitzinger \& Skidmore, in press). This is in spite of the fact that professionals, activists and researchers in this field continually note the importance of the broader social context of abuse, informing readers that: 'sexual abuse of children is an inherent condition of our society' (Miller-Perrin,C \& Wurtele, 1988 ) or that 'the real battle lies in making fundamental changes in a society that allows and even encourages child sexual abuse' (DeYoung, 1988 p111). Yet it is precisely this area which is under-therorised and under-explored within the mainstream literature and prevention initiatives. A comprehensive review of articles about prevention concludes that although concern about the societal structure and political framework 'crops up in every review of this nature [...] These are proposals only, not accompanied by specific recommendations or trials.' (Helfer, 1982)

Although this review was published in 1982 the situation remains very similar in the 
1990s. The books and articles about 'prevention' often end with an almost ritual genuflection in the direction of the changes needed in 'society at large' but this is rarely the main focus of attention (Murray \& Gough, 1991; Finkelhor, D \& Strapko, 1988; Conte \& Fogarty, 1988; Tharinger et al , 1988). As Conte and his colleagues point out: 'While many prevention professionals recognise that fundamental change in power relationships in families and in society from a sexist to egalitarian distribution will be necessary to prevent sexual victimisation, not enough has been done to link political and cultural life and sexual victimisation.' (cited in Tharinger et al. 1988).

The Zero Tolerance campaign is an exception to this rule. It is the first major advertising campaign in Britain with the stated aim of attempting to challenge social attitudes towards physical and sexual assaults against women and girls. The Zero Tolerance campaign is a public awareness initiative which starts from the premise that intervening against sexual violence, including child sexual abuse, depends, at least in part, on addressing prevailing social attitudes: people's ability to believe that it happens, their refusal to tolerate such abuse and their willingness to act on their suspicions. The campaign also draws on the perception that sexual abuse is a 'problem of masculine sexuality' (Smart, 1989, 50). Most perpetrators of sexual assault are male and there are links between the social construction of male sexuality and the potential for abusive behaviour (Dominelli, 1986; Finkelhor, 1982; Hearn, 1988; Hollway, 1981; Kelly, 1988). The campaign explicitly addresses child sexual abuse as a crime of male violence and draws links between the various abuses perpetrated against women and girls throughout their lives.

The Zero Tolerance campaign was developed by Edinburgh District Council Women's Committee in consultation with groups working with victims/survivors of domestic violence and sexual assault and drew on research into initiatives undertaken in other countries, especially Canada (see Westmount Research Consultants Inc, 1992). Part of the campaign involved four poster advertisements, two of which concerned sexual violence against girls and are shown below [see Fig 1 $\& 2]$. The advertisements were displayed on billboards throughout Edinburgh as well as in indoor sites such as public houses, libraries, and sports centres. [\#INSERT FIG 1 \& 2 NEAR HERE] Subsequently, other statements were sited on prominent placards in Edinburgh's main shopping street. These included statements such as: ' $85 \%$ of rapists are men known to the victim', 'Male abuse of Power is a Crime' and 'No Man has the Right'. The local newspaper ran a series of articles on each of the subjects addressed by the posters and, as a new and somewhat controversial initiative, the campaign attracted the attention of the national British press and television.

\section{ii. Method}

The Zero Tolerance campaign is on-going: a fresh series of posters were launched in 1994. The campaign has now also been taken up and adapted for use in many other parts of the UK, including London (where it focuses on domestic violence and uses images of male perpetrators rather than women or children). The research presented here, however, is soley concerned with the first six months of the original Zero Tolerance initiative in Edinburgh. The evaluation was concerned with people's acceptance of, and belief in, the campaign messages and their reactions to each of the campaign statements and advertisements. It explored questions such as: had they discussed the campaign with anyone, had it made them think about the subject and 
had it altered their opinion about anything? The research was carried out using a combination of a street survey and focus group discussions.

The street survey: The questionnaire study was a site-specific street survey designed to explore the opinions of a representative sample of people in Edinburgh.

Questionnaires were returned for 228 respondents and the interviewees broadly reflected the demographic composition of Edinburgh apart from the fact that interviews were conducted with slightly more people under 30 than those in other age categories.

The focus group method: Focus group methodology is a way of addressing the fact that people do not react to an advertisement, film or newspaper article in a social or cultural vacuum, but frame and develop their understandings in interaction with others (Morgan, 1988; Kitzinger, 1994). Focus groups make use of the interaction between group members in order to explore people's views and are particularly useful in providing information about the 'meaning' of a campaign within a social setting. The qualitative work also allowed for the collection of detailed data about people's responses to each advertisement.

Whereas the street survey respondents were selected in order to provide a representative sample, the focus groups were targeted in a way which would provide access to a diversity of opinion. Thus, while the survey provides meaningful statistical data, the group discussions provide elucidation of particular perspectives and debates. The groups consisted of twelve 'lay' groups and five 'special interest' groups from in and around Edinburgh and Glasgow. Each one consisted of about 6 people. All sessions were tape-recorded. The lay groups covered a range of demographic variables (e.g. an age range of 12-62 years old). They included members of the Christian Women's Guild; a youth group and members of the Transport and General Workers Union. The special interest groups all had some type of specialist knowledge around crime, sexual violence or family conflict, albeit from some very different perspectives. These groups included police officers, SHAKTI black women's group, an incest survivors self-help group, and workers in a marriage counselling service.

\section{iii. Findings}

The street survey findings: There was a high-level of recognition of, and support for, the campaign. Sixty-four percent of the street survey respondents had seen or heard something about the campaign and 39\% of these had actually discussed the Zero Tolerance campaign with someone else. Seventy-nine percent of those who had noticed the campaign felt 'very' or 'quite positive' about it. Just $6 \%$ described their feelings as negative (5\% 'quite' and $1 \%$ 'very negative'). General support for the principles behind a public awareness initiative was also evident in the fact that almost $80 \%$ of all the street survey respondents agreed with the statement that "Edinburgh is right to take the lead in drawing attention to domestic violence and abuse" and $72 \%$ agree that "The public as a whole do not know enough about violence and abuse". [For a full report of the street survey see: Kitzinger \& Hunt, 1994]

The focus group findings: The focus group work revealed that many of the group participants welcomed the campaign as a demonstration that Edinburgh District 
Council cared about the female citizens of the city. They felt it was thoughtprovoking and were particularly glad that the advertisements addressed men instead of simply focusing on self-protective strategies for the potential victims of male violence. The campaign was identified as a useful trigger for mobilising action against such violence.

It was sometimes seen as inevitable that some people would react against the Zero Tolerance material but the campaign was welcomed for relieving survivors of the burden of revealing the secret of widespread abuse:

'It is not because somebody is standing there saying "I was raped as a child" that it's there. If it's just a big picture on a billboard, then nobody's personally responsible for bringing that up. That's kind of the burden that we leave survivors with... [...] nobody speaks about child abuse, except survivors, [...] [The campaign is] pressing everybody's button that hasn't been pressed before. It unleashes whatever they want to bring up. [...] [The Council] definitely deserve a round of applause for that, because they're relieving the burden of bringing it up into every-day life from the people who are affected by it. [Grp 10, Self-help group, f]. (The letters 'f' and 'm' are used to indicate the gender of the speaker).

The posters about the rape and sexual abuse of girls were identified as particularly powerful and, in some ways, were the most widely accepted aspect of the campaign. For many research participants the picture on the advertisement 'From 3 to 93...' was particularly effective in bringing home the 'horror' of rape and even people who had reservations about the Zero Tolerance initiative as a whole often said they liked this poster, partly because the young girl and old women were clearly seen as 'innocent victims' or, as one woman stated: 'They are not asking for it' [Women's Guild, f] This poster also made them think hard about what motivates rapists:

Rather than just a couple of columns in a newspaper you're actually seeing an old person and a young person and you're wondering about the sexual attraction of these people [...] what kind of sexual gratification anybody could get from having intercourse with a 93 year old or a 3 year old, you know, where is the pleasure? Is it a sexual pleasure or is it a power issue when you've got to dominate somebody else? [Police Officers, $m$ ].

The focus group data also revealed some of the reasons for disliking the campaign. These included the belief that exposing such abuse was bad for the public image of the city and gave the wrong impression to tourists, that the advertisements might cause distress and that they were 'scare-mongering'. Further discussion of such points revealed that, although some people believed that the advertisements might cause distress, no one felt that it had had that effect on them personally. Far from feeling traumatised by the campaign, those group participants who volunteered that they had been sexually abused during childhood said that the posters actually made them feel less isolated. As one survivor of abuse commented, rather than feeling that the posters were 'rubbing her nose in it': 'It's the silence that's rubbing our noses in it, that common notion of "Keep it quiet", that's shoving your nose down all the time.' [SelfHelp grp, f] Similarly, although some group participants suggested that the campaign might make people unnecessarily frightened, no one seemed to think that the campaign had, in fact, unreasonably increased their own fears for their safety. 
However the campaign did increase some people's fears for their children, although this was not necessarily seen as a negative effect:

I don't want to think about anybody abusing my kids [...] The worst nightmare I have is in that picture. [...] I've left my children in the house and the last thing I want to think about tonight is that they might be abused. It's a very good advert. [JK: Why is it good?] Because it terrifies me! [JK: Why is it good to terrify you? ] If it's making me aware that someone could abuse my children, then that is a bloody good advert. [Transport worker, $m$ ]

Concern was expressed about the message that 'husbands' and 'fathers' could be responsible for abuse. Some people were worried that this would make women and children distrust men that they knew. At the same time it was evident that most of the respondents did not believe that anyone they knew could actually behave in that way. They persisted in believing that an abuser was more likely to be a stranger, although they still believed that it was vital to convey this basic information. As one man commented: That bit at the bottom - 'husband, father, stranger'...That makes me feel uneasy, and anything that makes me feel uneasy, makes me think. That's what's really good about it. I go to work and put my bairns in the nursery, what's going on in the nursery? What's going on with my bairns? [Transport workers, $m$ ]. In another group, three girls (all aged about 14) commented on the 'stranger danger' lessons that they had been taught at school and argued that they should have been told about the possibility of incestuous assault:

f1: They should really [give that information] [...] if their father came up to them ...

f3: They'd be too scared to tell anyone what was happening.

f5: Because you love your dad and your dad loves you and you would just think that was right and you can't go telling anyone 'cause that's right.

f1: Even if your dad comes up to you and starts touching you or something they could show them what they should do. [Youth Group]

Some people, however, felt that the campaign was unnecessarily antagonistic and 'sexist'. They criticised the focus on female victims of sexual assault and several expressed surprise that a campaign against violence against women should address sexual assaults against girls. As one woman commented on seeing one of the posters: 'Oh, I thought Zero Tolerance was about something else. I thought it was about violence against women. I didn't realise it dealt with children as well'. A point to which her colleague responded by saying: 'Well, they are women, women in the making.' [laughter] [Academics, f]. Addressing child sexual abuse as a problem for girls was seen as potentially exclusive and undermining for boys: "I felt sorry for the boys who were left out of that' [Self-Help grp, f]. Focusing on child sexual abuse as a problem for girl-children was also seen by some as undermining the 'dignity' of the problem:

'[...] it's kind of making abuse a little girlies' thing. You know, there is something in that that is kind of denying it the dignity it deserves. It is something that happens to people and is perpetrated by people. [Grp 10, Self-help group, f]

There was also a great deal of debate within the groups about the focus on male perpetrators. The gender of the abuser was, according to some people, irrelevant and the attention given to 'male abuse of power' was often seen (by both men and women) 
as 'insulting' and 'divisive'. In particular some men felt that the campaign only located them as 'potential rapists':

It could be my little girl [...] that's raped [...][But] I'm rejected on the same side as the rapist.[...] I want to know if there is going to be any tolerance of us who are prepared to do something about it or are we all going to be put on the same side of the fence and told that we are all criminals? [Transport workers, $m$ ]

It is presumably, at least in part, this feeling of alienation that contributed to male respondents to the street survey being much more likely to feel negative about the campaign than women (12\% of male respondents reported any negative response as opposed to just $2 \%$ of women). However, the street survey showed that most men still felt positive about the campaign and this was reflected within the group discussions. Some male felt challenged by, rather than alienated from the campaign. One man, for example, commented that the advertisements made him think about how he used power over his children: 'Every time I've shouted at my kids I've sat back and thought 'how could I have done that better?' [Transport workers, $m$ ]; another commented: 'there's a message for every male here [.. I I don't think men can say 'this is nothing to do with me' [Office workers, $m$ ] . Some of these people felt that identifying a continuum of abusive male behaviour was an essential part of the campaign and that it was quite justified for the Women's Committee to give priority to targeting male violence:

$O K$, there are women who are violent towards women and children but it's not anywhere near the same kind of percentage [...] We are talking about violence against women and children and it mostly comes from men so it has to be looked at. It's not just a coincidence that it's mostly men. [Women's Aid workers, f]

The group discussions also suggested that the statements which some men found most problematic - statements such as 'No man has the right' and 'Male abuse of power is a crime' - could be positively empowering for some women: ' [It's] like some injection of power, that brings you courage [...] It sets you on par with a man' [Shakti women's group, f]; 'It gives women strength [...] It's making you aware of your rights as a woman, you don't have to accept it, you don't have to lie back' [Neighbours, f]; 'It lets you know that you're a person in your own right' [Gingerbread, $f$ ]

Another focus of people's responses to the advertisements was the nature of the statistics that they presented. Some unease was expressed about the idea that one out of every two girls would experience some form of abuse 'from flashing to rape'. Some people quite simply did not believe it. Others felt that defining abuse so broadly was ridiculous and misleading: 'Maybe a father will take a wee lassie in the bath with him and wash her. Is that going to be classed as sexual abuse, because she's seen you naked? You know, from the ridiculous to the sublime!' [Transport workers, f]

By contrast, other research participants were very positive about the inclusive definition of abuse and agreed that flashing should be taken seriously and that it was important to understand all these behaviours as part of the same continuum. Most significantly of all, regardless of whether or not they 'approved' of this strap-line, the phrase seemed to open the way for some people to talk about their own experiences of childhood abuse. It was very striking that debate about the phrase 'from flashing to 
rape' seemed to enable research participants to reveal incidents which they had never mentioned before to the friends, neighbours or colleagues in that group. Such personal revelations during the course of the research sessions had an unexpected consequence. During the course of the discussion people who had originally rejected the statistics as exaggerated, came to accept them. It seems that people become more likely to accept that such abuse is widespread if they know someone who has been assaulted or come to realise that friends or colleagues may have in fact been abused, but have never talked about it.

This realisation that the experience of childhood abuse may be hidden by adults, and by children at the time, was further reinforced by the nature of the pictures on the advertisements which showed children who appeared happy and secure. 'Well, there's domestic bliss. You know, there's kids playing in a safe environment with their dolly'; 'A happy home, isn't it? You can imagine mum down the stairs, just about to shout up "Tea's ready'". [Police Officers, $m$; Neighbours, $f$ ]

Looking at the pictures on their own, knowing that the advertisement was part of a campaign about violence, people often suggested that the caption must read something like 'It would be nice if all little girls felt this safe' or 'Don't spoil our innocence' [Marriage Counselling Service workers, $f$; Neighbours, f]. They were often startled by the actual caption and stated that the rather serene scenes portrayed in the pictures did not seem to 'fit' with the text. This led some people to complain that the pictures were 'misleading' : 'She doesn't look like a victim' [Gingerbread members, f]. However this very contrast could make these advertisements particularly thoughtprovoking and could confront people with their own stereotypes about 'the look' of an abused child: 'They look just like an ordinary wee couple of girls - like any body's kids, and you realise something's going to happen to them - it could happen to your kid' [Residents, f]. This seemed to help people to realise that anyone might be a victim of such treatment: 'It's not necessarily obvious. I mean your friend's child could be experiencing it and you wouldn't be able to detect it' [Neighbours, f]. It also challenged the notion that only working class or neglected children are abused: 'It could be someone living in a mansion, it could be someone living in a hovel.'

[Transport workers, $m$ ]; 'Even if a girl's brought up nice, [...] she can still be abused'. [Residents, f]. As a worker from Women's Aids commented: The NSPCC posters always show kids that are really poor. It's like poverty-stricken kids and I'm not denying that it happens to them but it's always this image that the kids are dirty, not clean and well looked after. And I'm glad that this image has come across now rather than these poor wee scrubby kids' [Women's Aid workers] ${ }^{1}$.

\section{i.v Conclusion}

The Zero Tolerance campaign succeeded in attracting the attention and gaining the approval of most of the people who were questioned in the street survey. It has also provoked considerable public debate. Concerns that the advertisements would causes unnecessary distress or unreasonable fear did not seem to be realised. Although there was some annoyance about the focus on male violence only a minority of the population were alienated by the material. The campaign caused some people to reflect on their own role as adults or men with power over children/women and helped to challenge certain misconceptions, such as the idea that you can 'tell by looking' if a child is being abused. 
On its own, however, the campaign, is 'merely' a public awareness campaign and research participants expressed a wish to see it result in concrete changes. In Edinburgh the existence of the campaign served as a focus for discontent about legal and policy issues and resulted in the formation of an independent pressure group called 'Stand-up', which is pushing for legal changes. For many research participants, it is this sort of follow-up work which is the vital ingredient: 'I've decided that the campaign was a brilliant idea [precisely] because there didnae seem like any sort of prior reference [...] If we're starting to have it plastered all over Princes Street, then I am hopeful that people like us, and anybody that is interested, will start to ask questions. [...] Concerned people will start to think 'Well, where can we find out about this?' [...] I'm looking on it as a first step. [Self-help group, f].

Looking on the Zero Tolerance campaign as a 'first step' in attempting to challenge the social climate within which abuse occurs would suggest that it has been a success. As the campaign is taken up and adapted in other parts of Britain it remains to be seen whether it can achieve its long-term aims.

A summary report or copy of the full report (describing the research as a whole) is available from: The Zero Tolerance Campaign, Edinburgh District Council Women's Committee, City Chambers, High St, Edinburgh EH1 1YJ

\section{REFERENCES}

Butler, S., (1986) Thinking about Prevention: a critical look In Nelson, M. and Clark, K. (Eds.) The Educator's Guide to Preventing child sexual abuse (pp. 6-14) Santa Cruz: Network Publications.

Conte, Jon. R. and Fogarty, Linda, (1989). Paper prepared for the special issue of Education and Urban Society

DeYoung, M., (1988). The good touch/bad touch dilemma: Child Welfare, LXVII (1) 61-68.

Dominelli, L.,1986 Father-Daughter incest: patriarchy's shameful secret: Critical Social Policy, 16, 8-22.

Finkelhor, D., (1982) Sexual Abuse: a sociological perspective: Child Abuse and Neglect 6 (1), 95-10.

Finkelhor, D., (1986). A Source Book on Child Sexual Abuse, Sage: London.

Finkelhor, D \& Strapko, N., (1988) Sexual Abuse Prevention: a review of evaluation studies. in Willis, D., Holder, E., and Rosenberg, M (eds) Child Abuse Prevention. (pp.1-27) Wiley, New York.

Hearn, J., (1988). Commentary. Child abuse: Violences and sexualities towards young people: Sociology, 22 (4), 531-544.

Helfer, R., (1982). A review of the literature on the prevention of child abuse and neglect: Child Abuse and Neglect, 6, 251-261.

Hollway, W., (1981) 'I just wanted to kill a woman' Why? The ripper and male sexuality': Feminist Review, 9, 33-41.

Kelly, L (1988) Surviving Sexual Violence. Polity, London.

Kitzinger, J., (1994). The methodology of Focus Groups: the importance of interaction between research participants: Sociology of Health and Illness 16 (1), pp103-122. 
Kitzinger, J., and Hunt, K. (1994) Evaluation of Edinburgh District Council's Zero Tolerance Campaign: The Full Report. Edinburgh District Council Women's

Committee, Edinburgh.

Kitzinger, J., and Skidmore, P (in press) Playing Safe: media coverage of child sexual abuse prevention strategies: Child Abuse Review, in press [this issue?]

Morgan, D. (1988) Focus Groups as qualitative research. Sage, London.

Miller-Perrin, C.L. and Wurtele, S.K. (1988). The child sexual abuse prevention movement: a critical analysis of primary and secondary approaches: Clinical Psychology Review, 8, 313-329.

Murray, K., and Gough, D. (eds) (1991) Intervening in child sexual abuse. Scottish Academic Press, Edinburgh.

Smart, C. (1989) Feminism and the power of law. Routledge, London.

Tharinger, D.J., Krivacska, J.J., Laye-McDonough, M., Jamison, L., Vincent, G.G., and Hedlund, A.D., (1988). Prevention of child sexual abuse: an analysis of issues, educational programs and research findings: School Psychology Review, 17 (4), 614634.

Trudell, B., Whatley, M.H., (1988). School sexual abuse prevention: unintended consequences and dilemmas: Child Abuse and Neglect, 12, 103-113

Westmount Research Consultants Inc., (1992). Evaluation of the Wife Assault

Prevention Campaign, Ontario Women's Directorate.

1 Charities may, of course, experience a tension between promoting images which attract donations, and those which are actually accurate. They may also be concerned not to use 'inaccessible' images. However, this research found that the middle-class image of the pictures did not necessarily prevent working-class people responding to, or identifying with the advertisements. They recognised the pictures as a stereotypical representation of a happy home ('It could be an advert for Habitat, or insurance') and were 'literate' in the dominant symbolism. The issue of representing white or black children is more problematic, for discussion see Kitzinger \& Hunt, 1993.

\section{ACKNOWLEDGEMENTS}

Thanks are due to all the research participants and to all the people who helped with the evaluation, especially Kate Hunt who took responsibility for the street survey, Hannah Bradby who conducted one of the focus groups and Linda Watson-Brown and the students who collected the street survey data. 